\title{
THE ASSOCIATIONS OF SELECTED LIFESTYLE PATTERNS AND LUNG CANCER RISK: AN EVIDENCE-BASED UPDATE
}

\author{
Joanna Kruk, ${ }^{1, A, B, C}$ Basil H. Aboul-Enein 2, D \\ ${ }^{1}$ Faculty of Physical Culture and Health Promotion, University of Szczecin, Poland \\ ${ }^{2}$ School of Health Sciences, University of South Dakota, USA \\ A Study Design; ${ }^{\mathrm{B}}$ Data Collection and Analysis; ${ }^{\mathrm{C}}$ Manuscript Preparation; ${ }^{\mathrm{D}}$ Revision of the Article and Final Approval
}

\author{
Address for corpespondence: \\ Joanna Kruk \\ University of Szczecin, Faculty of Physical Culture and Health Promotion \\ Al. Piastów 40b/6, 71-065 Szczecin, Poland \\ E-mail: joanna.kruk@univ.szczecin.pl
}

\begin{abstract}
Ahstract. Diagnosis of lung cancer (LC) has been fraught with difficulty and by the time of definitive diagnosis, most patients are in later stages of the disease. Epidemiological studies have demonstrated that lifestyle behaviors play an etiological role in LC risk; however data in the literature on this topic often appears inconclusive or require further study. Understanding of the mechanisms operating between lifestyle patterns and their impact on LC is important for the disease's prevention and treatment. The purpose of this study was to review the current evidence on the role of diet, body mass index (BMI), physical activity, smoking, alcohol consumption, and sex hormone use in LC development based on meta-analyses, systematic reviews and previously published epidemiologic studies. Regarded as the foremost cause of $L C$, evidence from studies have indicated that tobacco smoking causes $L C$. Additionally, exposure to outdoor air pollution and/or occupational-related exposures increase LC risk. Further, frequent consumption of red meat, processed meat increases adenocarcinoma and squamous cell carcinoma. Inverse associations between the disease risk and BMI $\geq 25 \mathrm{~kg} / \mathrm{m}^{2}$, higher level of physical activity, and fruit and vegetable consumption with a high frequency were reported. Future studies are warranted to validate the association between histologic subtypes of $L C$ and lifestyle patterns.
\end{abstract}

Key Worlls: lung cancer, physical activity, diet, body weight, alcohol consumption, smoking, sex hormone

\section{Introduction}

Lung cancer (LC) is the leading cause of total cancer incidence and mortality worldwide with a 5 -year survival rate of $<10 \%$ (Ferlay et al., 2015; Jemal et al., 2011; Zahir, Mirtalebi, 2012). Four major histologic subtypes of LC have been differentiated: small-cell carcinoma, large-cell carcinoma, adenocarcinoma, and squamous carcinoma (Devesa, Bray, Vizcaino, Parkin, 2005). Adenocarcinoma and squamous carcinoma are the most frequently diagnosed subtypes of the total number of $\mathrm{LC}$; which accounts for about $30-40 \%$ and $30 \%$, respectively. $\mathrm{LC}$ incidence varies among geographical regions particularly in the developed countries, with considerable increases observed in some developing countries (Ferlay et al., 2015). Epidemiologic studies have recognized tobacco smoking as 
the dominant risk factor for LC (Wu, et al., 2014b; Yuan et al., 2012), accounting for $90 \%$ of male cases and $79 \%$ of female cases (Khan, Afag, Mukhtar, 2010). There are estimates that the risk of LC development among lifelong active smokers is 20-40 times higher than nonsmokers (Ulas et al., 2015). Additionally, second hand tobacco smoke has been established as a risk factor with the percentage of LC attributed to passive smoking accounting for 3-5\% (Emaus, Thune, 2015). According to the National Cancer Institute, non-smoking individuals exposed to passive smoking have about a $20 \%$ increased risk of the disease compared to non-smokers and individuals not exposed to secondhand smoke ( $\mathrm{NCl}, 2011)$. However, approximately $10-20 \%$ of LC cases have been identified among people who never smoked (Khan et al., 2010). Furthermore, there is a potential synergistic interaction between tobacco smoking and occupational and environmental exposures to lung carcinogens, like polycyclic hydrocarbons, asbestos, radon, arsenic, chromium, nickel, and cadmium (Environmental Protection Agency 2011; Kim, Jahan, Kabir, Brown, 2013; Raaschou-Nielsen et al., 2013; Saracci, 1987; Straif et al., 2009). Age, race, and a positive family history of LC have been confirmed as risk factors for the disease (Lissowska et al., 2010; Matakidou, Eisen, Houlston, 2005; Pinsky, 2006). During the last five decades, research has focused on the role of diet, physical activity, and other modifiable lifestyle patterns in the etiology of some cancers, including LC. Given the presence of several gaps in the findings in etiology of LC, such as the cancer in people who never smoked, a small percentage of smokers with diagnosed cancer, and difference in incidence rates only in men, a higher risk of LC in African Americans compared with other racial/ethnic groups (National Cancer Prevention, 2015), a growing body of research has focused on modifiable lifestyle factors that may modify the risk in active and passive smokers or to increase susceptibility to the disease in people who never smoked. Some studies have presented the benefits of regular physical activity of moderate intensity (Buffart et al., 2014; Emaus, Thune, 2011; Mao et al., 2003), obesity (Thun et al., 2008), and fruit and vegetable consumption (Bunn Jr., 2012; Butler et al., 2013; Ruiz, Hernández, 2014). Others have reported significant or non-significant higher risk of LC associated with consumption of animal fats, red meat, and processed meat (Gnagnarella et al., 2013a; Gnagnarella et al., 2013b; Lam et al., 2009), and alcohol consumption (Korte et al., 2002). However, some research findings on the association of lifestyle determinants with $L C$ require further examination of the current evidence. Because $L C$ is a multifactorial disease with a high incidence rate in men and women, it is important to continue updating the current evidence on the role of modifiable risk factors in the disease etiology. Providing further evidence on mechanisms of lifestyle factors that influence LC risk may help in the primary prevention of the disease thereby reducing mortality. This paper examines the most updated evidence on the relationship between the major modifiable risk factors and their contribution to LC development and risk. The aim of this paper is not intended to be a review on this topic, but to highlight key risk factors and relevant examples of lifestyle patterns on LC risk.

\section{Diet and lung cancer pisk}

Epidemiological studies investigating the causal association between nutrition and LC have shown that dietary risk factors may accounts for 30-35\% of modifiable risk factors for cancer (Ruiz, Hernández, 2014) due to the influence of nutrition on the regulation of the cell cycle (WCR/AICR, 2007). Poor dietary patterns are second to tobacco smoking as a major risk of LC worldwide. Dietary patterns are classified into two categories as it relates to disease prevention: (1) diets characterized by a rich consumption of vitamins, fiber, fruits and vegetables, olive oil, whole grains, green tea, and fish; or (2) diets characterized by an increased consumption of animal fats, red 
meat, processed meat, saturated fats, and refined sugars. Evidence have been proposed regarding the strength of the diet - LC risk association as the relationship has been found to be dependent on histologic subtypes of LC and smoking status (Büchner et al., 2010); though, data on this dependence seems to be inconsistent. This lack of consistency may be attributable to the limited number of studies on this topic. A recent systematic review by Koutsokera et al. (2013) studying the relationship between dietary patterns and LC found that 11 cohort and case-control studies suggested a reduction in LC risk with consumption of fruits and vegetables. The authors also found an increased LC risk with higher intake of red and processed meat. The group concluded that most researchers observed an inverse association between fruit and vegetable consumption and LC risk, and only some studies found a beneficial effect with only fruit consumption. A recent population-based case-control study of 2,101 primary LC cases in Italy by Lam et al. (2009) that was not included in the above review reported an elevated risk of LC among smokers by $80 \%$ and by $70 \%$ for red and processed meat consumption, respectively. In addition, the group reported higher LC risk among people who never smoked $(\mathrm{OR}=2.4,95 \% \mathrm{Cl}=1.4-4.0$ for red meat intake and $\mathrm{OR}=2.5,95 \% \mathrm{Cl}=1.5-4.2$ for processed meat intake). Another recent review of epidemiological research by Ruiz, Hernández (2014), which examined the literature dating back prior to October 2013, on the preventive roles of omega-3 and omega- 6 fatty acids against several cancers including LC, concluded that there is no clear evidence regarding the preventive roles of these compounds. The relationship between diet and the risk of LC was confirmed in a few recent studies not included in the aforementioned reviews. For example, Butler et al. (2013) reported an increased risk of lung adrenocarcinoma with high-temperature cooked meat intake by $51 \%$ (hazard ratio, $H R=1.51)$ using data from a large prospective study from Singapore $(1,130$ cases identified from 61,321 subjects who never smoked). In contrast, the group observed no association between fried meat consumption and LC risk of non-adrenocarcinoma, especially among subjects who never smoked. Another recent prospective study (4,336 heavy smokers, among them 178 cases) also reported increased LC risk by $73 \%$ for frequent red meat intake (Gnagnarella et al., 2013a). Further, the group showed a 44\% significant decrease in the risk (HR $=0.56$, $95 \% \mathrm{Cl}=0.31-0.99$ ) for one or more cups of tea consumed daily compared to non-tea consumers and a $90 \%$ risk reduction for a Mediterranean-style diet $(\mathrm{HR}=0.10,95 \% \mathrm{Cl}=0.01-0.7)$. Consistent with this study, Mukti et al. (2014) observed an increased risk of LC by $93 \%$ with high intake of red meat in a case-control study of Bangladeshi people. Additionally, a previous study reported a significant risk reduction with vegetable fat consumption (Gnagnarella et al., 2013b). Takata et al. (2013) large cohort study of Chinese men (61,491 individuals, 359 cases, 68.8\% identified as smokers) indicated that consumption of green leafy vegetables and carotenoid-rich vegetables were significantly associated with lower LC risk by $28-56 \%$. In turn, Lugman et al. (2014) studied the association between dietary patterns and LC risk in a case-control study in Pakistan (400 cases and 800 controls). The study findings showed that $\mathrm{OR}$ for $\mathrm{LC}$ was positively associated with consumption of red meat $(\mathrm{OR}=2.9,95 \% \mathrm{Cl}=1.8-4.7)$, chicken $(\mathrm{OR}=2.8,95 \% \mathrm{Cl}=1.4-4.9)$, tea $(\mathrm{OR}=1.8,95 \% \mathrm{Cl}=1.2-2.6)$, and coffee $(\mathrm{OR}=1.8,95 \% \mathrm{Cl}=1.1-2.8)$. In contrast, consumption of vegetables, juices or fruits, decreased LC risk by $70 \%$, and consumption of milk by $40 \%$.

Several plausible mechanisms have been hypothesized to explain how processed meat and fresh red meat increase cancer risk. Meats are rich sources of protein but during the high temperature processing of meats, saturated fatty acids and other compounds such as heterocyclic amines, N-nitroso compounds, aldehydes, polycyclic aromatic hydrocarbons are produced (Lam et al., 2009; Ramirez, Estévez, Morcuende, Cava, 2004; Ruiz, Hernández, 2014; Sugimura, Wakabayashi, Nakagama, Nagao, 2004). Experimental studies recognized these compounds as both mutagenic and carcinogenic. For example, $\mathrm{N}$-nitroso compounds have been found to induce 
DNA damage (Eichholzer, Gutzwiller, 1998). Usage of nitrate or nitrite salts for the preservation and color of meats contribute to the production of DNA-damaging nitrosamines (ACS). In addition, meats, which are rich sources of total fat, saturated fat, and cholesterol, increase the concentration of secondary bile acids that are able to participate in carcinogenesis. Further, dietary heme iron in meat may contribute to an increased LC risk as donor or receptor of an electron, being involved in the Fenton reaction (Fe (II) $+\mathrm{H}_{2} \mathrm{O}_{2} \rightarrow \mathrm{Fe}(\mathrm{III})+\mathrm{HO}^{\bullet}+\mathrm{OH}^{-}$) (Valko et al., 2007). The Fenton reaction and the reduction of the iron ion by superoxide anion radical, $\mathrm{O}_{2}^{\overline{0}}\left(\mathrm{Fe}(\mathrm{III})+\mathrm{O}_{2}^{\overline{0}} \rightarrow \mathrm{Fe}(\mathrm{II})+\mathrm{O}_{2}\right)$ has been recognized as a key source of the most powerful oxidant in a cell such as hydroxyl radical, $\mathrm{HO}^{\circ}$. In organisms overloaded in iron disturbance between oxidant formation and the antioxidant defense capacity in cells with excessive production of reactive oxygen species (ROS) and nitrogen species is related to oxidative stress (OS). Such a cell's state characterized by excessive generation of ROS is a key regulatory mechanism for cancer stem cells and cancer due to DNA damage directly and/or to formation of $\mathrm{N}$-nitroso containing compounds, thus plays a considerable role in the initiation and progression of cancer (Filaire et al., 2013; Lam et al., 2009). Although several previous and recent studies have suggested that a diet rich in red meat and processed meat may serve as risk factors for LC; there are also many studies that report inconsistent findings. The Second Expert Panel concluded that the epidemiological evidence for these dietary patterns are limited and inconsistent, respectively (WCR/AICR, 2007). The lung organ is directly exposed to environmental pollutants and ROS produced during chronic inflammation, especially in tobacco smokers. The oxidants can induce modification of DNA, lipids, proteins, and activate the mitogen-activated protein kinase signaling that lead to inflammation and activation of nuclear transcription factors (Valko et al., 2007). Several consequences of DNA damage in lung under OS conditions have been reported, among them replication errors and genomic instability. It is theoretically accepted that prooxidant reactions play a key role in the initiation, promotion, and progression of cancer (Filaire et al., 2013). Therefore, dietary antioxidants are especially important in the protection against LC, particularly for smokers as inhibitors of free radicals that are present in cigarette smoke (Weng, Yen, 2012). Dietary antioxidants may reduce DNA damage caused by ROS, thereby protecting against LC risk. The prevention of cancer through a diet rich in fruits and vegetables have been attributed to the presence of vitamins (A, B6, B12, C, D, folic acid), minerals, carotenoids, fiber, flavonoids, indoles, and phenolic compounds. Many of these compounds are inhibitors of ROS and play an important role as low molecular weight antioxidants, enhancing the endogenous antioxidant system. Polyphenolic compounds may protect against cancer as antioxidants by several metabolic reactions due to the modification in cell adhesion, migration, and angiogenesis (Garcia-Tirado, Rieger-Reyes, Saz-Peiro, 2012; Weng and Yen 2012). Weng, Yen (2012) reported that the polyphenolic compound resveratrol (occurring in high concentration in red grapes), caffeic acid, and pomegranate flavonoids were found to protect against LC. Vitamins and minerals, found in fruits and vegetables, can act synergistically and serve a beneficial protective effect against cancer. Interestingly, vitamin and mineral supplementation in pills that are equivalent to levels found in fruits and vegetables were not found to have such protective effects. Moreover, there is evidence that high-dose supplement intake has the potential to increase cancer risk (Albanes, 1999). In recent years, evidence has been suggested that natural glycoproteins are important biologically active compounds with anticancer properties. Present in plant cells; glycoproteins found in green tea possess strong antioxidant potential. Anti-tumor actions of glycoproteins are attributed among others, to the influence of immune system response, the reduction of inflammation, killing of tumor cells, activation of tumor necrosis factor (TNF), and the blocking of tumor cell differentiation. Recent studies provide evidence that immune function-enhancing pharmaceuticals that mitigate side effects of chemotherapeutics have been found to be effective 
in LC therapy (Yuan, Liu, Dai, Song, 2015). While an increased consumption of fruits and vegetables seem to have a protective effect against LC risk due to their antioxidant ability, some studies reported no protective association (Liu, Sobue, Otani, Tsugane, 2004). Further studies are warranted to investigate how particular components of a diet could affect histological subtypes of LC, which also take into account gender and smoking status. Moreover, the consumption of fruits and vegetables may influence cancer risk through their influence on overall energy intake. In addition, individuals that consume a diet rich in vegetables and fruits are usually more physically active. Due to a diverse range of genetic abnormalities of LC cells, Wood, Pernemalm, Crosbie, Whetton, (2014) reported possible gene - environmental interactions, dependence of DNA repair mechanisms, and inflammation of an individual's genes. The report from World Cancer Research Fund/American Institute for Cancer Research (2007) stated that the evidence regarding non-starchy vegetable intake and a decreased risk of $L C$ to be "limited suggestive", and frequent intake of fruits and vegetables rich in carotenoids as "probable".

\section{Physical activity and luny cancer risk}

In the past 25 years, there has been a focused interest in the preventive role of moderate or high levels of physical activity (PA) and cancer risk (primary prevention) and the use of PA as a safe complementary treatment for patients with cancer (secondary prevention) (Albrecht, Taylor, 2012; Emaus, Thune, 2011; Kruk, Czerniak, 2013; Lee et al., 2012; Lee, Sesso, Paffenbarger, 1999; Lowe, Watanabe, Baracos, Courneya, 2010; McTiernan, 2008; Speck et al., 2010). The term PA, as described in epidemiologic studies, has included household, occupational, recreational (for pleasure or competitive aim), and transportation activities (Caspersen, Powell, Christensen, 1985). In order to categorize energy expenditure, a combination of frequency, duration, and intensity of activity should be accounted, based on a resting metabolic score (MET), i.e. an equivalent to quiet sitting which for the average

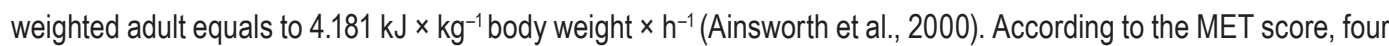
levels of PA intensity are distinguished in epidemiologic studies: sedentary or inactive (1.0 $\leq 1.6 \mathrm{MET}$, e.g. sleeping, watching TV), light (1.6 $\leq 3.0 \mathrm{MET}$, e.g. yoga), moderate (3.0 $\leq 6.0 \mathrm{MET}$, e.g. walking), and vigorous ( $\geq 6.0 \mathrm{MET}$, e.g. running) in order to categorize energy expenditure (Norton, Norton, Sadgrove, 2010). For primary prevention, there is limited evidence from observational studies that physical activity protects against LC risk according to a 5-degree scale of the Second Panel judgments (WCR/AICR, 2007) ("convincing, probable, limited suggestive, limited - not conclusion, substantial effect on risk unlikely"). To date, the biological mechanisms by which PA may reduce LC risk are not fully understood, but there are several plausible mechanisms hypothesized linking PA to reduced LC risk (Anzuini, Battistella, Izzotti, 2011; Emaus, Thune, 2011; Friedenreich 2011; Goldstraw et al., 2011; Missaoui et al., 2011; Thune, Lund, 1997). Multiple mechanisms may act cooperatively and some may depend on factors such as level of PA, LC subtype, and smoking status (Lynch, Neilson, Friedenreich, 2011). The first possible mechanism includes increased pulmonary function that may reduce concentration of carcinogens in the airways and duration of air-way exposure to inhaled carcinogens among individuals engaged in PA especially of vigorous intensity (Thune, Lund, 1997). PA may also help to neutralize ROS, which is a known cancer initiator, thus reducing DNA damage caused by these environmental pollutants (Rundle, 2005). It has been suggested that an increase in pulmonary ventilation and perfusion may decrease the risk of small cell-carcinoma and adenocarcinoma cancer subtypes situated mainly in the periphery of the lung. This suggestion, however, appears to be applicable in male patients (Thune, Lund, 1997). Inhaled chemical carcinogens and ROS have been recognized to react with DNA of lung and bronchus cells (Asami et al., 1997; Church, Pryor, 1985). One hypothesis suggests that 
PA may be preventive by increasing DNA repair ability through an up-regulation of antioxidant defense systems. Another hypothesis suggests that regular long-term PA improves immune system function through an increase of the number and activity of natural killer cells, and macrophages, and interleukins (IL-1 and IL-2) (Nieman, Pedersen, 1999; Shephard, Rhind, Shek, 1995). A third hypothesis postulates reduction of inflammation. Recent studies have suggested a direct association between chronic inflammation and cancer risk (Klaunig, Kamendulis, Hoceva, 2010; Reuter et al., 2010). This is due to the inflammatory responses to the chemical or particulate exposures, wounds, or microbial infection (Emaus, Thune, 2011). PA of moderate intensity may help reduce generation of proinflammatory cytokines, such as IL-1, IL-6 and tumor necrosis factor-alpha (TNF-a), thereby reducing C-reactive protein (CRP) (Panagiotakos et al., 2005). Both interleukins and TNF-a may affect the growth and differentiation of lymphocytes and stimulate proliferation and differentiation of immune cells. There is, however, no scientific consensus or clarity on the association of PA and reduction of inflammatory cytokines (Sprague et al., 2008). The forth hypothesis in the preventive role of PA is the influence of insulin growth factor-1 (IGF-1)/insulin growth factor binding protein-3 (IGFBP-3) ratio. Higher concentrations of IGF-1 were reported to be linked with increased LC risk (Friedenreich, Orenstein, 2002; Gonullu et al., 2005; Mao, 2003). IGF-1 may act as a mitogen thereby increasing cell proliferation and differentiation (Lynch et al., 2011). In contrast, high levels of IGFBP-3 were reported to be associated with decreased risk (Mao et al., 2003). However, some studies do not confirm an association between IGF factors and LC risk (Ahn et al., 2006; Renehan et al., 2004). Strong and coherent evidence exists for the role of increased oxidative stress in carcinogenesis (Filaire et al., 2013; Klaunig et al., 2010; Kruk, Duchnik, 2014; Laszlo et al., 2014; Manda, Nechifor, Neagu, 2009; Valluru, Dasari, Wudayagiri, 2014; Yeon et al., 2011). Smoking and environmental carcinogenic inhalations are examples of exogenous sources of ROS and nitrogen species. In this respect, regular PA of moderate intensity is hypothesized to protect against LC risk by increasing of levels of antioxidant enzymes (Rundle et al., 2005) and tissue resistance against ROS damage (Kruk, 2011). ROS not only damages DNA but also stimulates inflammatory signal transduction pathways via activation of nuclear factor (NF-k $\beta$ ). Moderate PA induces an expression of antioxidant genes through the activation of nuclear factor 2 (Nrf2) that participates in the expression of antioxidants (Filaire et al., 2013). These previously described mechanisms that mediate the relationship between regular PA and LC risk may operate synergistically or independently adverse consequences.

Studies from randomized controlled trials (RCT) have provided further insight on the role of PA in cancer etiology. A review of RCT evidence postulates that PA may have a small to moderate effect on improving the concentrations of biomarkers that are potentially involved in carcinogenesis (Winzer et al., 2011). The epidemiologic evidence on the preventive role of PA and LC risk is growing but warrants further examination. A previous metaanalysis by Tardon et al. (2005) that evaluated studies published between 1966 and October 2003 (eight cohort studies and three case-control studies), adjusted for smoking and others confounders, found a protective effect of $\mathrm{PA}$ dependent on its intensity (the combined odds ratio $(\mathrm{OR}), \mathrm{OR}=0.87,95 \% \mathrm{Cl}=0.79-0.95$ for moderate leisure time $\mathrm{PA}$ and $\mathrm{OR}=0.70,95 \% \mathrm{Cl}=0.62-0.79$ for vigorous activity). The risk reduction was stronger among women compared to men for both levels of activity. Emaus, Thune (2011) analyzed 20 cohort studies (published between 1989 and 2009) and seven population-based case-control studies (published between 1991 and 2008). They found that total and recreational PA may reduce the risk of LC by $20-50 \%$ among men and by $20-30 \%$ among women; the cancer risk correspondingly decreased with increasing levels of PA, suggesting a dose-response effect. Another review of 21 study samples published between June 1989 and May 2011 concluded that results of the studies were inconsistent; where 10 studies demonstrated a decreased risk of LC among moderate and high physically active 
subjects, and 11 studies reported no association (Koutsokera et al., 2013). An analysis of the studies published between 1996 and October 2003 indicated that leisure-time PA may protect against LC risk. Evidence of a negative association between PA and LC risk was confirmed in a subsequent meta-analysis of 14 prospective studies (1,644,305 participants, 14,074 cases) published between 1989 and 2009 (Sun, Shi, Gao, Xu, 2012). The authors found that both high and medium levels of PA were linked with a significant decrease in LC risk among total participants (men and women) compared to individuals characterized by low level of activity (RR $=0.77,95 \%$ $\mathrm{Cl}=0.73-0.81$ and $\mathrm{RR}=0.87,95 \% \mathrm{Cl}=0.83-0.90$, respectively). A recent meta-analysis of seven cohort studies and one case-control study demonstrated that PA reduced $L C$ risk significantly $(R R=0.82,95 \% \mathrm{Cl}=0.77-0.87$ ), however the authors did not observe dose-response relationships between PA levels and LC risk (Buffart et al., 2014). Further, they reported no differences in the risk among heavy and light smokers. Steindorf (2013) reported that 29 publications supported recreational PA to be effective in reducing LC risk by up to $20-30 \%$ among women and $20-50 \%$ among men. Another recently published meta-analysis by Zhong et al. (2016) reviewed 12 cohort studies and six case-control studies (2,468,470 participants, 26,453 cases) and demonstrated a protective effect against $L C$ risk of any amount of $P A(R R=0.79,95 \% \mathrm{Cl}=0.73-0.86)$ and similar risk reduction among individuals engaged in high PA compared to low PA. Further evidence in the protective association between PA and LC risk was confirmed in a few recent epidemiologic studies not included in the aforementioned analyses. Schmidt et al. (2012) analyzed 158 LC-affected and 144 control cases from the Cologne Smoking Study (CoSmoS) (a retrospective case-control study) and found that PA was associated with a reduced risk of LC in current or former smokers. Individuals who were physically active at least one hour/week were at a significantly lower risk compared to those not physically active $(\mathrm{OR}=0.53,95 \% \mathrm{Cl}=0.28-0.97)$; however, the authors were not able to characterize precisely the intensity and frequency of the subjects' activity. Parent et al. (2011) in a case-control study (857 LC cases and 533 controls) conducted in Montreal, Canada, found that participation in sports and/or outdoor activities of average once weekly or more for at least 6 months decreased LC risk by about $31 \%(\mathrm{OR}=0.69,95 \% \mathrm{Cl}=0.52-0.91)$. The authors also observed a statistically insignificant reduction in LC risk with lifelong occupational PA (OR $=0.86$, $95 \% \mathrm{Cl}=0.49-1.52$ ). For the combined occupational and recreational PA during adult life, a $34 \%$ significant LC risk reduction was observed. Sormunen et al. (2004) examined the association between lifetime PA and LC risk in a cohort of 2448 elite male athletes and 1712 controls in Finland between 1986 and 2010. The research group found a strong LC risk reduction; with a standardized incidence ratio of $0.40,95 \% \mathrm{Cl}=0.27-0.55$ among athletes. Further, the authors concluded that, on the whole, athletes were less likely to develop any cancers than the general population, especially lung and renal cancer as a consequence of less frequent smoking and other healthy lifestyle patterns. A prospective cohort study by Lam et al. (2013) of 158,415 participants with no history of smoking involved in the NIH-AARP Diet and Health Study (532 cases, identified over 11 years of follow-up) found that individuals who spent $\geq 3$ hours/day sitting had an increased LC risk by $32 \%$ compared to those who spent $<3$ hours/day sitting. Interestingly, they did not observe an association for participation in vigorous PA. A recently published prospective population-based cohort study (73 LC cases identified during an average follow-up of 20 years of 2305 individuals with no history of cancer at baseline) of Finnish men examined the relationship between cardiorespiratory fitness (CRF) and leisure-time PA (LTPA) (Pletnikoff et al., 2016). The study demonstrated a protective effect of CRF against $L C(R R=2.89 ; 95 \% \mathrm{Cl}=1.14-7.22, p=0.02)$ accounting for $\mathrm{VO}_{2}$ max mean $40.49 \mathrm{~mL} / \mathrm{kg} / \mathrm{min}$ relative $20.28 \mathrm{~mL} / \mathrm{kg} / \mathrm{min}$ in the model adjusted for age, year of examination, family history of cancer, smoking, education, alcohol consumption, vegetable and fruits intake. However, in a multivariate model, the relationship between LTPA 
and LC risk was found to be insignificant. A lack of association between LTPA and LC in fully adjusted models were reported by Brizio et al. (2016) based on a case-control study (81 cases, 168 controls) in Brazil.

PA appears to play an important beneficial role for patients with LC. Patients with LC experience a poor health-related quality of life and a high prevalence of psychological stress. According to a systematic review of 16 studies on the role of PA interventions for patients with non-small cell LC, PA decreased symptoms of the disease, improved quality of life, and physical capacity (Granger et al., 2011). Further, CRT studies that evaluated the effects of PA intervention on fatigue and quality of life patients with LC showed improvement of fatigue, quality of life, and a beneficial effect on physical and psychological symptoms (Dhillon et al., 2012; Jensen et al., 2014). A latest study by Wang et al. (2015) that evaluated the influence of chronic diseases and PA on quality of life among LC survivors in Shanghai (China), found that PA exerts a beneficial effect on quality of life only in those survivors with chronic diseases.

Previous epidemiological studies have consistently shown that PA plays an important role in the reduction of risk of LC risk, particularly in current or former smokers and improved physical well-being of cancer survivors. The majority of studies reported that recreational and total PA reduced LC risk on average by $20-30 \%$ in women and $20-50 \%$ in men, although, most of these studies on association between LC risk and PA involved only men with some authors reporting a protective effect of PA on the disease in men but not in women (Thune, Lund, 1997). Other studies indicated that PA of moderate or vigorous intensity is linked with a decreased risk among both genders (Sun et al., 2012). The influence of PA on carcinogenesis can vary depending on intensity, frequency, and duration of activity, smoking history, energy intake, body weight, gender, alcohol consumption, genetic susceptibility, and other environmental factors. There are limited data regarding the relationship of LC risk with PA in people who never smoked; although several studies suggested a lack of difference in the association regarding smoking status (Lee et al., 1999; Mao et al., 2003). It has been suggested that regular PA of moderate/high intensity improves pulmonary function, thereby reducing the concentration of carcinogen compounds and their deposition in the airways and reduces the duration of the carcinogenic agents-airway interaction. Moreover, PA causes changes in the concentration of pro-cancer growth factors such as IGFs and IGFBPs, reduces inflammation, enhances immune function, and improves DNA repair. Several researchers have underlined the beneficial role of regular PA of moderate intensity in adapting to oxidative stress by up-regulating superoxide dismutase and glutathione peroxidase. In contrast, single exhaustive PA can increase oxidative stress that is hypothesized to play an etiological role in LC development. In the systematic review of the existing evidence the World Cancer Research Fund 2007 rated the evidence as "limited suggestive" that PA lowers LC risk (WCRF/AICR, 2007). The observed inconsistency of findings may be due to the fact that there are possible interactions between PA, diet, smoking, and obesity. Individuals who are physically active tend to lead healthier lifestyles i.e. less likely to smoke, to be obese, to drink alcohol, and frequently consume vegetables and fruits compared to those who are more sedentary (Kruk, 2010).

\section{Excess hody weight and lung cancer pisk}

Overweight (Body Mass Index, BMI $\geq 25.0 \leq 30 \mathrm{~kg} / \mathrm{m}^{2}$ ) and/or obesity (BMI $\geq 30 \mathrm{~kg} / \mathrm{m}^{2}$ ) (WCRF/AICR 2007) were reported as significant risk factors for most cancers (Reeves et al., 2007; Renehan 2011; Renehan, Roberts, Dive, 2008). There are several proposed biological mechanisms to explain this association, among them are: high levels of insulin resulting from increased concentrations of leptin, resistin, TNF-a, and fatty acids released from adipose tissue. These biomolecules may promote cellular proliferation and inhibit apoptosis (Calle, Kaak, 2004). 
The association of overweight/obesity with LC risk is not well described and warrants further investigation. Some researchers reported that low BMI $\left(<18 \mathrm{~kg} / \mathrm{m}^{2}\right)$ increased LC risk independently of smoking status, weight loss, and other confounders among both genders and for women who never smoked (Kabat, Wynder, 1992). A recent cohort study with 12,052 males by Li et al. (2015) reported increased LC risk by $80 \%$ among Asian men with BMI $<18.5 \mathrm{~kg} / \mathrm{m}^{2}$ compared to those with BMI $18.5-24.9 \mathrm{~kg} / \mathrm{m}^{2}$. Further, the authors found that men with BMI $\geq 25 \mathrm{~kg} / \mathrm{m}^{2}$ had a significant decrease in $\mathrm{LC}$ risk $(\mathrm{RR}=0.65,95 \% \mathrm{Cl}=0.49-0.88)$ and those with $\mathrm{BMI} \geq 30 \mathrm{~kg} / \mathrm{m}^{2}$ had a nonsignificant decrease in $\mathrm{LC}$ risk ( $\mathrm{RR}=0.64,95 \% \mathrm{Cl}=0.30-1.37$ ). A meta-analysis of 12 studies selected between 1966 and 2013 confirmed a significant increased LC risk in men with $\mathrm{BMl}<18.5 \mathrm{~kg} / \mathrm{m}^{2}$, significant decreased risk in men with $\mathrm{BMI} \geq 25 \mathrm{~kg} / \mathrm{m}^{2}$ and $\mathrm{BMl} \geq 30 \mathrm{~kg} / \mathrm{m}^{2}$, compared with normal weight subjects. When the authors stratified on subgroups based on geographical regions, a significantly increased risk by $47 \%$ in individuals with $\mathrm{BMI} \leq 18.5 \mathrm{~kg} / \mathrm{m}^{2}$ was found only among East-Asian men but not among other populations. The authors also found that excess BMI compared to normal BMI significantly decreased chromosomal damage, therefore LC risk. These findings support the existing literature that increased methylation at the hypoxia-inducible factor (HIF)-3 alpha locus in adipose tissue and in blood can decrease the expression of HIF-3a of a factor able to potentially mediate LC and gene-obesity interaction (Pasanen, Heikkilä, Rautavuoma, 2010). A previous meta-analysis of prospective studies by Renehan et al. (2008) showed a significant decrease in the risk with a $5 \mathrm{~kg} / \mathrm{m}^{2}$ increase in BMl in a dose-response effect. Also, further evidence from another meta-analysis (Yang et al., 2013) of cohort and case-control studies found that overweight and obesity may protect against LC risk in both genders. The authors underlined that there is a varying effect of BMI on the development of $L C$ in men and women. The mechanism of inverse association of BMI with LC warrants further investigation.

\section{Smoking, alcohol consumption, and lung cancep risk}

Tobacco smoking has been firmly established as a major primary risk factor for LC; smokers have an 8-13 times higher risk compared to non-smokers (Katanoda, Marugame, Salka, 2008; Lugman et al., 2014; Mukti et al., 2014; Wu et al., 2014b). About 4000 chemical constituents, including pharmacologically active, toxic, mutagenic and carcinogenic compounds such as $\mathrm{N}$-nitrosamines and alkaloids have been identified in cigarette smoke (Asami et al., 1997; Fowles, Dybing 2003; Yuan et al., 2012). Exposure to tobacco carcinogens generated by active smokers (environmental tobacco smoke) can cause LC in nonsmokers (Besaratinia, Pfeifer, 2008; Couraud et al., 2012). According to Vollset, Tverdal, Gjessing (2006), smoking is responsible for 1.8 million cancer deaths per year worldwide and $80-90 \%$ of LC deaths are among people 40-70 years of age (Kamsa-Ard et al., 2013). The risk increases with the initiation of smoking at an early age, as well as longer smoking periods. Smoking has contributed considerably to health care costs. For example in 2008, the total economic cost of LC caused by smoking reached in 2008 \$2.234 billion in men and $\$ 870.0$ million in women in South Korea (Oh et al., 2012), and $\$ 12.0$ million in Morocco (Tachfouti et al., 2012). Recent advances have been found to help elucidate the differences in the development of LC between smokers and non-smokers (Yano et al., 2011; Wu et al., 2014b). Wu et al. (2014b) have carried out a meta-analysis of 19 case-control studies that included 2,287 LC cases (63.4\% smokers). The authors found an approximately $30 \%$ higher risk for Ras-association domain family 1 isoform A gene hypermethylation (RASSF1A) in smokers than in non-smokers. This gene was found to reduce tumorigenicity in vivo and its damage resulting from methylation associated with cigarette smoking which can be an important agent in LC etiology. This, however, does not explain the high risk observed among smokers, which may point to possible 
effects of other variables (age, gender, ethnicity, lifestyle). Smoking exerts various influences on the occurrence of specific subtypes of LC, from the strongest initiator in small-cell carcinoma to the weakest in adrenocarcinoma (Koutsokera et al., 2013). Polycyclic aromatic hydrocarbons (PAHs) and the most potent compound nitrosamine present in cigarette smoke and occupational exposure were reported to cause chromosomal damage, thereby causing genomic instability (Asami et al., 1997; Kim et al., 2013). However, even statistical models accounting for BMI, PA, and alcohol consumption linked with smoking and LC failed to eliminate the strong confounder of cigarette smoking. A large prospective cohort study (Lam et al. 2013) of 532 LC cases identified from 158415 individuals who never smoked found no beneficial effects of BMI at baseline or middle age on LC risk compared to Li et al. (2015) study. Differences in the effect of BMI on LC risk based on smoking status are still not well recognized. One possible explanation for these differences suggests that LC in people who never smoked has a unique etiology occurring mainly as the adenocarcinoma subtype and EGFR mutations (Lam et al., 2013). Cigarette smoking is often reported to be linked with poor dietary patterns and alcohol intake (Alberg, 2002). Several studies have examined the potential link between alcohol intake and LC risk. A pooled analysis of cohort studies (7 prospective studies, 399,767 participants and 3,137 LC cases) indicated a 21\% increase in LC risk in men and a 16\% increase in women for intake $\geq 30 \mathrm{~g}$ of alcohol/day compared to those consuming no alcohol (Freudenheim et al., 2005). The authors observed an increased risk of LC among men who never smoked with an intake of $\geq 15 \mathrm{~g}$ alcohol/day compared to men who declared no alcohol consumption ( $R R=6.38,95 \% \mathrm{Cl}=2.74-14.9)$ and a lack of association in smokers.

Findings from epidemiological studies evaluating the effect of both alcohol intake and smoking on LC risk indicated that an increased risk was reported more frequently in hospital case-control studies than in populationbased case-control studies (Korte et al., 2002). However, the findings from some epidemiologic studies often appeared conflicting. Further studies are needed in order to clarify whether alcohol consumption acts as an additional risk factor in smokers. Several biological mechanisms have been proposed to explain the effect of alcohol consumption on LC risk (Chiolero et al,. 2006; Dupont et al., 1998; Kukiełka, Cederbaum, 1992; Manautou, Carlson, 1991; Wright, McManaman, Repine, 1999). One proposal suggests that a reaction between ethanol and alcohol dehydrogenase generating acetaldehyde of what may be a substrate for xanthine oxidoreductase, which, in turn, triggers generation of superoxide radical, $\mathrm{H}_{2} \mathrm{O}_{2}$, and hydroxyl radical in the Fenton reaction (Jaganjac et al., 2013). Another proposed mechanism involves the effect of ethanol on NADH and NADPH dependent production of ROS (Kukiełka, Cederbaum, 1992) owing to the enhancement of cigarette smoke carcinogens (Hamajima et al., 2002).

\section{Oral contraceptive use, hormone replacement therapy, and lung cancer pisk}

With the understanding that LC is a multifactorial disease that can be dependent on gender, some evidence have suggested a link between hormonal factors and LC (Siegfried, 2010). Consequently, it is important to present the current state of evidence regarding the possible role of estrogens in LC development. It is well documented that most carcinogens require activation to generate intermediates or products able to form covalent binding with DNA bases. According to the mechanism of steroidal estrogen metabolism, summarized by Kruk and Aboul-Enein (2006), the transformation of estrogens involve production of several products such as ROS, semiquinones, and catecholestrogens that are capable of modifying DNA, RNA, proteins and cause lipid peroxidation. Research on the association between estrogen use and cancer risk have found an increased risk for some cancers (e.g. breast, liver) and a decreased risk in others (Wu et al., 2014a). Several meta-analyses have examined links between the 
use of estrogens and LC risk, however their findings appear inconclusive (Chen, Cai, 2009; Pesatori et al., 2013; Wu et al., 2014a). Pesatori et al. (2013) reported a statistically significant decrease in risk compared to Baik et al. (2010) who found an increased risk among long time estrogens users (>5 years). Chen, Cai (2009), however, observed no association. Similarly, Wu et al. (2014a), in an updated meta-analysis of 14 cohort and case-control studies found a lack of a significant association between oral contraceptive use and LC risk. However, the authors observed a $26 \%$ decrease in risk among European oral contraceptive users and a $10 \%$ borderline significant effect in women with adrenocarcinoma. The differences in these findings may, in part, be explained by the decreased concentration of estrogen content and the addition of progesterone acting as an antiestrogen (Qin et al., 2013). Moreover, estrogens can interact with compounds from tobacco smoke and influence their metabolism as well as estrogen receptor signaling. Their effects may be dependent on histologic subtypes (Siegfried, 2010). Further studies on large groups of cases able to perform analyses with histological subgroups of LC, dose, and duration of estrogen use, adjusting for tobacco smoking and other potentially recognized confounders are warranted.

\section{Conclusion}

There is growing scientific evidence indicating that lifestyle factors may exert independent effects on LC development. Knowledge of the relationship between LC risk and lifestyle components provide an opportunity to reduce the incidence of this disease. There is supportive evidence which indicates that about $33 \%$ of LC may be preventable by health changing behaviors (Gauci, Delikata, 2011). However, several unanswered questions remain due in part, to the fact that smoking is a very strong factor for LC risk and attenuates the relationship between LC risk and other lifestyle determinants, even after adjustment for this confounder. Tobacco smoke exposure, arsenic, and asbestos have been consistently established as risk factors for LC. However, the literature have shown that this type of cancer may never develop among current smokers while occurring among individuals who never smoked. The current literature underlines the importance of limiting the consumption of animal fats and red meat, increasing vegetable, fruits, and whole grain intake, avoiding excessive weight gain and at least 150 minutes of regular PA of moderate intensity or 75 minutes of vigorous intensity each week as healthy lifestyle factors in LC prevention. Primary LC prevention continues to be the avoidance or cessation of tobacco smoking. Consistent with these findings, the American Institute for Cancer Research (2010) estimates that 36\% of LC cases "could be prevented annually through a healthy diet, regular physical activity, and being lean". In addition, a role of synergistic reactions between cigarette smoking and alcohol consumption or asbestos exposure have been found to change an individual's susceptibility to LC. Evidence shows that modifiable lifestyle patterns are among environmental risk factors that play an important role in the etiology of LC. However, studies evaluating the effects of environmental and lifestyle risk factors on the development of $L C$ require further multidisciplinary studies. These suggested studies should include large sample sizes and potential confounders that characterize the mechanisms by which lifestyle determinants may influence certain histologic subtypes of LC development. Identification of all subclasses of LC and their markers is a priority. Molecular biology research would help ascertain information on DNA, RNA, and proteins damage and the genetic transformation. Of interest are findings dealing with the subclass classification for $L C$ datasets as one of the analysis tools reported over last few years of gene expression research (Engchuan, Chan, 2015). This will help to raise public health in adopting healthier lifestyle patterns and develop strategies and interventions for both the prevention and treatment of LC. 


\section{References}

Ahn, J., Weinstein, S.J., Snyder, K., Pollak, M.N., Virtamo, J., Albanes, D. (2006). No association between serum insulin-like growth factor (IGF)-1, IGF-binding protein-3, and lung cancer risk. Cancer Epidemiol Biomarkers Prev, 15, 2010-2112.

AICR/WCRF. Policy and Action for Cancer Prevention, 2009 Cancer Facts \& Figures 2010, ACS. www.aicr.org Americans can prevent $1 / 3$ of the most common cancers.

Ainsworth, B.E., Haskell, W.L., Whitt, W.C., Irwin, M.L., Swartz, A.M., Strath, S.J., et al. (2000). Compendium of physical activities: an update of activity codes and MET intensities. Med Sci Sports Exerc, 32, 498-516.

Albanes, D. (1999). Beta-carotene and lung cancer: a case-control study. Am J Clin Nutr, 69 (6), 1345-1350.

Alberg, A. (2002). The influence of cigarette smoking on circulating concentrations of antioxidant micronutrients. Toxicology, 180, 121-137.

Albrecht, T.A., Taylor, A.G. (2012). Physical activity in patients with advanced-stage cancer: a systematic review of the literature. Clin J Oncol Nurs, 16 (3), 293-300.

American Cancer Society Guidelines on Nutrition and Physical Activity (ACS) retrieved from www.cancer.org/healthy/ eathealthygetactive/acsguidelinesonnutritionphysicalactivityforcancerprevention/acs-guidelines-on-nutrition-andphysical-activity-for-cancer-prevention-guidelines.

Anzuini, F., Battistella, A., Izzotti, A. (2011). Physical activity and cancer prevention: a review of current evidence and biological mechanisms. J Prev Med Hyg, 52, 174-180.

Asami, S., Manabe, H., Miyake, J., Tsurudome, Y., Hirano, T., Yamaguchi, R., et al. (1997). Cigarette smoking induces an increase in oxidative DNA damage, 8-hydroxydeoxyguanosine in a central site of the human lung. Carcinogenesis, 18, 1763-1766.

Baik, C.S., Strauss, G.M., Speizer, F.E., Feskanich, D. (2010). Reproductive factors, hormone use, and risk for lung cancer in postmenopausal women, the Nurses' Health Study. Cancer Epidemiol Biomarkers Prev, 19 (10), 2525-2533.

Besaratinia, A., Pfeifer, G.P. (2008). Second-hand smoke and human lung cancer. Lancet Oncol, 9 (7), 657-666.

Brizio, M.L.R., Hallal, P.C., Lee, I.M., Domingues, M.R. (2016). Physical activity and lung cancer: a case-control study in Brasil. J Phys Act Health, 13 (3), 257-261.

Büchner, F.L. Bueno-de-Mesquita, H.B., Linseisen, J., Boshuizen, H.C., Kiemeney, L.A., Ros, M.M., et al. (2010). Fruits and vegetables consumption and the risk of histological subtypes of lung cancer in the European prospective investigation into cancer and nutrition (EPIC). Cancer Causes Control, 21, 357-371.

Buffart, L.M., Singh, A.S., van Loon, E.C.P., Vermeulen, H.I., Brug, J., Chinapaw, M.J. (2014). Physical activity and the risk of developing lung cancer among smokers: a meta-analysis. J Sci Med Sport, 17, 67-71.

Bunn, P.A. Jr. (2012). Worldwide overview of the current status of lung cancer diagnosis and treatment. Arch Pathol Lab Med, 136, 1478-1481.

Butler, L.M., Montague, J.A., Koh, W.P., Wang, R., Yu, M.C., Yuan, J.M. (2013). Fried meat intake is a risk factor for lung carcinoma in a prospective cohort of Chinese men and women in Singapore. Carcinogenesis, 34, 1794-1799.

Calle, E.E., Kaak, R. (2004). Overweight, obesity and cancer: epidemiological evidence and proposed mechanisms. Nat Rev Cancer, 4, 579-591.

Caspersen, C.J., Powell, .KE., Christensen, G.M. (1985). Physical activity, exercise, and physical fitness: definitions and distinctions for health-related research. Public Health Rep, 100, 126-131.

Chen, X., Cai, L. (2009). Meta-analysis of the effects on hormone replacement therapy and oral contraceptives associated with female lung cancer risk. Wei Sheng Yan Jiu, 38 (6), 672-676.

Chiolero, A., Wietlisbach, V., Ruffeux, C., Paccaud, F., Cornuz,J. (2006). Clustering of risk behaviors with cigarette consumption: a population-based survey. Prev Med, 42, 348-353.

Church, D.F., Pryor, W.A. (1985). Free radical chemistry of cigarette smoke and its toxicological implications. Environ Health Perspect, 64, 111-126.

Couraud, S., Zalcman, G., Milleron, B., Morin, F., Souquet, P.J. (2012). Lung cancer in never smokers - a review. Eur J Cancer, 48, $1299-1311$.

Devesa, S.S., Bray, F., Vizcaino, A.P., Parkin, D.E. (2005). International lung cancer trends by histologic type: male:female differences diminishing and adenocarcinoma rates rising. Int J Cancer, 117, 294-299.

Dhillon, H.M., van der Ploeg, H.P., Bell, M.L., Boyer, M., Clarke, S., Vardy, J. (2012). The impact of physical activity on fatigue and quality of life in lung cancer patients: a randomised controlled trial protocol. BMC Cancer, 12, 572, DOI: 10.1186/1471-2407-12-572. 
Dupont, I., Lucas, D., Clot, P., Menez, C., Albano, E. (1998). Cytochrome P450 2E1 inducibility and hydroxyethyl radical formation among alcoholics. J Hepatol, 28, 564-571.

Eichholzer, M., Gutzwiller, F. (1998). Dietary nitrates, nitrites, and N-nitroso compounds and cancer risk: a review of the epidemiologic evidence. Nutr Rev, 56, 95-105.

Emaus, A., Thune, I. (2011). Physical activity and lung cancer prevention. Recent Results Cancer Res, 186, 101-133.

Engchuan, W., Chan, J.H. (2015). Pathway activity transformation for multi-class classification of lung cancer dataset. Neurocomputing, $165,81-89$.

Environmental Protection Agency: Exposure to radon causes lung cancer in non-smokers and smokers alive. Washington, DC: Environmental Protection. Agency, 2011.

Ferlay, J., Soerjomataram, I., Dikshit, R., Eser, S., Mathers, C., Rebelo, M., et al. (2015). Cancer incidence and mortality worldwide: sources, methods and major patterns in GLOBOCAN 2012. Int J Cancer, 136 (5), E359-386.

Filaire, E., Dupuis, C., Galvaing, G., Aubreton, S., Laurent, H., Richard, R., et al. (2013). Lung cancer: what are the links oxidative stress, physical activity and nutrition. Lung Cancer, 82, 383-389.

Fowles, J., Dybing, E. (2003). Application of toxicological assessment principles to the chemical constituents of cigarette smoke. Tobacco Control, 12, 424-30.

Freudenheim, J.L., Ritz, J., Smith-Warner, S.A., Albanes, D., Bandera, E.V., van den Brandt, P.A., et al. (2005). Alcohol consumption and the risk of lung cancer: a pooled analysis of cohort studies. Am J Clin Nutr, 82, 657-667.

Friedenreich, C.M. (2011). Physical activity and breast cancer: review of the epidemiologic evidence and biologic mechanisms. Recent Results Cancer Res, 188, 125-139.

Friedenreich, C.M., Orenstein, M.R. (2002). Physical activity and cancer prevention: etiologic evidence and biological mechanisms. J Nutr, 132, 3456-3464.

Garcia-Tirado, J., Rieger-Reyes, C., Saz-Peiro, P. (2012). Effects of flavonoids in the prevention of lung cancer: systematic review. Med Clin, 139, 358-363.

Gauci, C., Delikata, N. (2011). Prevention of cancer through lifestyle change and screening. J Malta College Pharm Pract, 17, $21-24$.

Gnagnarella, P., Maisonneuve, P., Bellomi, M., Rampinelli, C., Bertolotti, R., Spaggiari, L., et al. (2013a). Red meat, Mediterranean diet and lung cancer risk among heavy smokers in the COSMOS screening study. Ann Oncol, 24 (10), 2606-2611.

Gnagnarella, P., Maisonneuve, P., Bellomi, M., Rampinelli, C., Bertolotti, R., Spaggiari, L., et al. (2013b). Nutrient intake and nutrient patterns and risk of lung cancer among heavy smokers: results from the COSMOS screening study with annual low-dose CT. Eur J Epidemiol, 28 (6), 503-511.

Goldstraw, P., Ball, D., Jett, J.R., Le Chevalier, T., Lim, E., Nicholson, A.G., et al. (2011). Non-small-cell lung cancer. Lancet, 378, 1727-1740.

Gonullu, G., Ersoy, C., Ersoy, A., Evrensel, T., Basturk, B., Kurt, E., et al. (2005). Relation between insulin resistance and serum concentrations of IL-6 and TNF- $a$ in overweight or obese women with early stage breast cancer. Cytokine, 31, $264-269$.

Granger, C.L., McDonald, C.F., Berney, S., Chao, C., Denehy, L. (2011). Exercise intervention to improve exercise capacity and health related quality of life for patients with non-small cell lung cancer: a systematic review. Lung Cancer, 72, 139-153.

Hamajima, N., Hirose, K., Tajima, K., Rohan, T., Calle, E.E., Heath, C.W. Jr, et al. (2002). Alcohol, tobacco and breast cancercollaborative reanalysis of individual data from 53 epidemiological studies, including 58,515 women with breast cancer and 95,067 women without the disease. Br J Cancer, 87, 1234-1245.

Jaganjac, M., Tirosh, O., Cohen, G., Sasson, S., Zarkovic, N. (2013). Reactive aldehydes-second messengers of free radicals in diabetes mellitus. Free Radical Research, 47 (Supp. 1), 39-48.

Jemal, A., Bray, F., Center, M.M., Ferlay, J., Ward, E., Forman, D. (2011). Global cancer statistic. CA Cancer J Clin, 61, 69-90.

Jensen, W., Oechsle, K., Baumann, H.J., Mehnert, A., Klose, H., Bloch, W., et al. (2014). Effects of exercise training programs on physical performance and quality of life in patients with metastatic lung cancer undergoing palliative chemotherapy - a study protocol. Contemp Clin Trials, 37 (1), 120-128.

Kabat, G.C., Wynder, E.L. (1992). Body mass index and lung cancer. Am J Epidemiol, 135, 769-774.

Kamsa-Ard, S., Promthet, S., Lewington, S., Burrett, J.A., Sherliker, P., Kamsa-Ard, S., et al. (2013). Association between smoking and mortality: Khon Kaen cohort study. Thailand. Asian Pac J Cancer Prev, 14 (7), 2643-2647.

Katanoda, K., Marugame, T., Salka, S. (2008). Population attributable fraction of mortality associated with tobacco smoking in Japan: a pooled analysis of free large-scale cohort studies. J Epidemiol, 18 (6), 251-264. 
Khan, N., Afag, F., Mukhtar, H. (2010). Lifestyle factor for cancer: evidence from human studies. Cancer Lett, 293, 133-143.

Kim, K.H., Jahan, S.A., Kabir, E., Brown, R.J. (2013). A review of airborne polycyclic aromatic hydrocarbons (PAHs) and their human health effects. Environ Int, 60, 71-80.

Klaunig, J.E., Kamendulis, L.M., Hocevar, B.A. (2010). Oxidative stress and oxidative damage in carcinogenesis. Toxicol Pathol, 38, 96-109.

Korte, J.E., Brennan, P., Henley, S.J., Boffetta, P. (2002). Dose-specific meta-analysis and sensitivity analysis of the relation between alcohol consumption and lung cancer risk. Am J Epidemiol, 155, 496-506.

Koutsokera, A., Kiagia, M., Saif, M.W., Souliotis, K., Syrigos, K.N. (2013). Nutrition habits, physical activity, and lung cancer: an authoritative review. Clin Lung Cancer, 14 (4), 342-350.

Kruk, J. (2010). Physical activity and breast cancer morbidity among women in the Region of Western Pomerania. Szczecin: Szczecin University Press.

Kruk, J. (2011). Physical exercise and oxidative stress. Medicina Sportiva, 15, 1, 30-40.

Kruk, J., Aboul-Enein, H.Y. (2006). Environmental exposure, physical activity and other behavioral risk factors in breast cancer. Curr Cancer Therapy Rev, 2 (1), 3-21.

Kruk, J., Czerniak, U. (2013). Physical activity and its relation to cancer risk: updating the evidence. Asian Pac J Cancer Prev, 14, 3993-4003.

Kruk, J., Duchnik, E. (2014). Oxidative stress and skin disease: possible role of physical activity. Asian Pac J Cancer Prev, 15 (2), 561-568.

Kukiełka, E,. Cederbaum, A.I. (1992). The effect of chronic ethanol consumption on NADH - and NADPH - dependent generation of reactive oxygen intermediates by isolated rat liver nuclei. Alcohol, 27, 233-239.

Lam, T.K., Cross, A.J., Consonni, D., Randi, G., Bagnardi, V., Bertazzi, P.A., et al. (2009). Intakes of red meat, processed meat, and meat mutagens increase lung cancer risk. Cancer Res, 69, 932-939.

Lam, T.K., Moore, S.C., Brinton, L.A., Smith, L., Hollenbeck, A.R., Gretchen, L., et al. (2013). Anthropometric measures and physical activity and the risk of lung cancer in never-smokers: a prospective cohort study. PLOS ONE, 8 (8), e70672.

Laszlo, R. Hartveg, P., Laszlo, S., Otto, S., Prokopchuk, D., Steinacker, J.M. (2014). Physical activity and cancer. OA Sports Medicine, $2(1), 1$.

Lee, I.M., Sesso, H.D., Paffenbarger Jr, R.S. (1999). Physical activity and risk of lung cancer. Int J Epidemiol, 28, 620-625.

Lee, I.M., Shiroma, E.J., Lobelo, F., Puska, P., Blair, S.N., Katzmarzyk, P.T., Lancet Physical Activity Series Working Group. (2012). Effect of physical inactivity on major non-communicable diseases worldwide: an analysis of burden of disease and life expectancy. Lancet, 380, 219-229.

Li, X., Bai, Y., Wang, S., Nyamathira, S.M., Zhang, X., Zhang, W., et al. (2015). Association of body mass index with chromosome damage levels and lung cancer risk among males. Sci Rep, 5, 9458. DOI: 10.1038/srep09458.

Lissowska, J., Foretova, L., Dąbek, J., Zaridze, D., Szeszenia-Dabrowska, N., Rudnai, P., et al. (2010). Family history and lung cancer risk: international multicentre case-control study in Eastern and Central Europe and meta-analyses. Cancer Causes Control, 21, 1091-1104.

Liu, Y., Sobue, T., Otani, T., Tsugane, S. (2004). Vegetables, fruit consumption and risk of lung cancer among middle-aged Japanese men and women. JPHC study. Cancer Causes Control, 15, 349-357.

Lowe, S.S., Watanabe, S.M., Baracos, V.E., Courneya, K.S. (2010). Physical activity interests and preferences in palliative cancer patients. Support Care Cancer, 18 (11), 1469-1475.

Lugman, M., Javed, M.M., Daud, S., Raheem, N., Ahmad, J., Khan, A.U. (2014). Risk factors for lung cancer in the Pakistani population. Asian Pac J Cancer Prev, 15 (7), 3035-3039.

Lynch, B.M., Neilson, H.K., Friedenreich, C.M. (2011). Physical activity and breast cancer prevention. In: K.S. Courneya, C.M. Friedenreich (eds.), Physical Activity and Cancer, Recent Results in Cancer Research, Chap. 2. Springer Verlag, Berlin Heidenberg, 186, 13-42.

Manautou, J.E., Carlson, G.P. (1991). Ethanol-induced fatty acid ethyl formation in vivo and vitro in rat lung. Toxicol, 70, 303-312.

Manda, G., Nechifor, M.T., Neagu, T.M. (2009). Reactive oxygen species, cancer and anti-cancer therapies. Curr Chem Biol, 3, $342-366$.

Mao, Y., Pan, S., Wen, S.W., Johnson, K.C., Canadian Cancer Registries Epidemiology Research Group. (2003). The Canadian Cancer. Physical activity and the risk of lung cancer in Canada. Am J Epidemiol, 158, 564-575. 
Matakidou, A., Eisen, T., Houlston, R.S. (2005). Systematic review of the relationship between family history and lung cancer risk. Br J Cancer, 93, 825-833.

McTiernan, A. (2008). Mechanisms linking physical activity with cancer. Nat Rev Cancer, 8, 205-211.

Missaoui, N., Hmissa, S., Landolsi, H., Korbi, S., Joma, W., Anjorin, A., et al. (2011). Lung cancer in central Tunisia: epidemiology and clinicopathological features. Asian Pac J Cancer Prev, 12, 2305-2309.

Mukti, R.F., Samadder, P.D., Emran, A., Ahmed, F., Bin Imran, I., Malaker, A., et al. (2014). Score based risk assessment of lung cancer and its evaluation for Bangladeshi people. Asian Pac J Cancer Prev, 15, 7021-7027.

National Cancer Institute (NCI): SEER Stat Fact Sheets: Lung and Bronchus Cancer. Bethesda, MD: National Institute of Health, 2011. Available online 2015: http://seer.cancer.gov/statfacts/html/lungb.html.

National Cancer Prevention - Lung Cancer Prevention Patient/Health Professional. Retrieved from http:www.cancer.gov/cancertopics/ pdq/prevention/lung/HealthProfessional/page//AllPages.

Nieman, D.C., Pedersen, B.K. (1999). Exercise and immune function: recent development. Sports Med, 27, 73-80.

Norton, K., Norton, L., Sadgrove, D. (2010). Position statement on physical activity and exercise intensity terminology. J Sci Med Sport, 13, 496-502.

Oh, I.H., Yoon, S.J., Yoon, T.Y., Choi, J.M., Choe, B.K., Kim, E.J., et al. (2012). Health and economic burden of major cancer due to smoking in Korea. Asian Pac J Cancer Prev, 13, 1525-1531.

Panagiotakos, D.B., Pitsavos, C., Chrysohoou, C., Kavouras, S., Stefanadis, C., ATTICA Study (2005). The association between leisure-time physical activity and inflammatory and coagulation markers related to cardiovascular disease: the ATTICA Study. Prev Med, 40, 432-437.

Parent, M.E., Rousseau, M.C., El-Zein, M., Latreille, B. (2011). Occupational and recreational physical activity during adult life and the risk of cancer among men. Cancer Epidemiol, 35, 151-159.

Pasanen, A., Heikkilä, M., Rautavuoma, K. (2010). Hypoxia-inducible factor (HIF)-3alpha is subject to extensive alternative splicing in human tissues and cancer cells and is regulated by HIF-1 but not HIF-2. Int J Biochem Cell Biol, 42 (7), 1189-1200.

Pesatori, A.C., Carugno, M., Consonni, D., Hung, R.J., Papadoupolos, A., Landi, M.T., et al. (2013). Hormone use and risk for lung cancer: a pooled analysis from the International Lung Cancer Consortium (ILCCO). Br J Cancer, 109, 1954-1964.

Pinsky, P.F. (2006). Racial and ethnic differences in lung cancer incidence: how much is explained by differences in smoking patterns? (United States). Cancer Causes Control, 17 (8), 1017-1024.

Pletnikoff, P.P., Tuomainen, T.P., Laukkanen, J.A., Kauhanen, J., Rauramaa, R., Ronkainen, K., et al. (2016). Cardiorespiratory fitness and lung cancer risk: A prospective population based cohort study. J Sci Med Sport, 19, 98-102.

Qin, J., Yang, T., Kong, F., Zhou, Q. (2013). Oral contraceptive use and uterine leiomyoma risk: a meta-analysis based on cohort and case-control studies. Arch Gynecol Obstet, 288 (1), 139-148.

Raaschou-Nielsen, O., Andersen, Z.J., Beelen, R., Samoli, E., Stafoggia, M., Weinmayr, G., et al. (2013). Air pollution and lung cancer incidence in 17 European cohorts: prospective analyses from the European Study of Cohorts for Air Pollution Effects (ESCAPE). Lancet Oncol, 14 (9), 813-822.

Ramirez, M.R., Estévez, M., Morcuende, D., Cava, R. (2004). Effect of the type frying culinary fat on volatile compounds isolated in fried pork loin chops by using SPME-GC-MS. J Agric Food Chem, 52 (25), 7637-7643.

Reeves, G.K., Pirie, K., Beral, V., Green, J., Spencer, E., Bull, D., et al. (2007). Cancer incidence and mortality in relation to body mass index in the Million Women Study: cohort study. BMJ, 335 (7630), 1134.

Renehan, A.G. (2011). Epidemiology of overweight/obesity and cancer risk. In: McTiernan A. ed. Physical Activity, Dietary, Caloric Restriction, and Cancer. Springer New York, Dordrecht, Heidelberg, London.

Renehan, A.G., Roberts, D.L., Dive, C. (2008). Obesity and cancer: pathophysiological and biological mechanisms. Arch Physiol Biochem, 114, 71-83.

Renehan, A.G., Tyson, M., Egger, M., Richard, F., Heller, R.F., Zwahlen, M. (2008). Body-mass index and incidence of cancer: a systematic review and meta-analysis of prospective observational studies. Lancet, 371, 569-578.

Renehan, A.G., Zwahlen, M., Minder, C., O'Dwyer, S.T., Shalet, S.M., Egger, M. (2004). Insulin-like growth factor (IGF)-1, IGF binding protein-3, and cancer risk: systematic review and meta-regression analysis. Lancet, 363, 1346-1353.

Reuter, S., Gupta, S.C., Chaturvedi, M.M., Aggarwal, B.B. (2010). Oxidative stress, inflammation, and cancer: How are they linked? Free Radic Biol Med, 49, 1603-1616.

Ruiz, R.B., Hernández, P.S. (2014). Diet and cancer: risk factors and epidemiological evidence. Mauritas, 77, $202-208$. 
Rundle, A. (2005). Molecular epidemiology of physical activity and cancer. Cancer Epidem Biomark Prev, 14, 227-236.

Rundle, A., Orjuela, M., Mooney, L., Tang, D., Kim, M., Calcagnotto, A., et al. (2005). Preliminary studies on the effect of moderate physical activity on blood levels of glutathione. Biomarkers, 10, 390-400.

Saracci, R. (1987). The interactions of tobacco smoking and other agents in cancer etiology. Epidemiol Res, 9, 175-193.

Schmidt. A., Jung, J., Ernstmann, N., Driller, E., Neuman, M., Staratschek-Jox, A., et al. (2012). The association between active participation in a sports club, physical activity and social network on the development of lung cancer in smokers: a case-control study. BMC Res Notes, 5, 2. DOI: 10.1186/1756-0500-5-2.

Shephard, R.J., Rhind, S., Shek, P.N. (1995). The impact of exercise on the immune system: NK cells, interleukins 1 and 2, and related responses. Exerc Sports Sci Rev, 23, 215-241.

Siegfried, J.M. (2010). Early changes in pulmonary gene expression followed tobacco exposure shed light on the role of estrogen metabolism in lung carcinogenesis. Cancer Prev Res (Phila), 3, 692-695.

Sormunen, J., Bäckmand, H.M., Sarna, S., Kujala, U.M., Kaprio, J., Dyba, T., et al. (2004). Lifetime physical activity and cancer incidence - a cohort study of former elite athletes in Finland. J Sci Med Sport, 17, 479-484.

Speck, R.M., Courneya, K.S., Masse, L.C., Duval, S., Schmitz, K.H. (2010). An update of controlled physical activity trials in cancer survivors: a systematic review and meta-analysis. J Cancer Survivorship, 4, 87-100.

Sprague, B.L., Trentham-Dietz, A., Klein, B.E., Klein, R., Cruickshanks, K.J., Lee, K.E., et al. (2008). Physical activity, white blood cell count, and lung cancer risk in prospective cohort study. Cancer Epidemiol Biomarker Prev, 17, $2714-2722$.

Steindorf, K. (2013). The role of physical activity in primary cancer prevention. Eur Rev Aging Phys Act, 10, 33-36.

Straif, K., Benbrahim-Tallaa, L., Baan, R., Grosse, Y., Secretan, B., El Ghissassi, F., et al. (2009). A review of human carcinogens - part C: metals, arsenic, dusts, and fibres. Lancet Oncol, 10 (5), 453-454.

Sugimura, T., Wakabayashi, K., Nakagama, H., Nagao, M. (2004). Heterocyclic amines: mutagens/carcinogens produced during cooking of meat and fish. Cancer Sci, 95 (4), 290-299.

Sun, J.Y., Shi, L., Gao, X.D., Xu, S.F. (2012). Physical activity and risk of lung cancer: a meta-analysis of prospective cohort studies. Asian Pac J Cancer Prev, 13, 3143-3147.

Tachfouti, N., Bekacemi, Y., Raherison, C., Bekkali, R., Benider, A., Nejjari, C. (2012). First data on direct costs of lung cancer management in Morocco. Asian Pac J Cancer Prev, 13, 1547-1551.

Takata, Y., Xiang, Y.B., Yang, G., Li, H., Gao, J., Cai, H., et al. (2013). Intakes of fruits, vegetables, and related vitamins and lung cancer risk: results from the Shanghai Men's Health Study (2002-2009). Nutr Cancer, 65 (1), 51-61.

Tardon, A., Lee, W.J., Delgado-Rodriguez, M., Dosemeci, M., Albanes, D., Hoover, R., et al. (2005). Leisure-time physical activity and lung cancer: a meta-analysis. Cancer Causes Control, 16, 389-397.

Thun, M.J., Hannan, L.M., Adams-Campbell, L.L., Boffetta, P., Buring, J.E., Feskanich, D., et al. (2008). Lung cancer occurrence in never-smokers: an analysis of 13 cohorts and 22 cancer registry studies. PLoS Med, 5 (9), e185.

Thune, I., Lund, E. (1997). The influence of physical activity on lung-cancer risk: a prospective study of 81,516 men and women. Int J Cancer, 70, 57-62.

Ulas, A., Tokluoglu, S., Kos, M., Silay, K., Akinci, S., Oksuzoglu, B., et al. (2015). Lung cancer in women, a different disease: survival differences by sex in Turkey. Asian Pac J Cancer Prev, 16, 815-822.

Valko, M., Leibfritz, D., Moncol, J., Cronin, M.T., Mazur, M., Telser, J. (2007). Free radicals and antioxidant in normal physiological function and human disease. Int J Biochem Cell Biol, 39, 44-84.

Valluru, L., Dasari, S., Wudayagiri, R. (2014). Role of free radicals and antioxidants in gynecological cancers: current status and future prospects. Oxid Antioxid Med Sci, 3, 15-26.

Vollset, S.E., Tverdal, A., Gjessing, H.K. (2006). Smoking and deaths between 40 and 70 years of age in women and men. Ann Intern Med, 144, 381-389.

Wang, J.W., Gong, X.H., Ding, N., Chen, X.F., Sun, L., Tang, Z., et al. (2015). The influence of comorbid chronic diseases and physical activity on quality of life in lung cancer survivors. Support Care Cancer, 23, 1383-1389.

Weng, C.J., Yen, G.C. (2012). Chemopreventive effect of dietary phytochemicals against cancer invasion and metastasis: phenolic acids, monophenol, polyphenol, and their derivatives. Cancer Treat Rev, 38, 76-87.

Winzer, B.M., Whiteman, D.C., Reeves, M.M., Paratz, J.D. (2011). Physical activity and cancer prevention: a systematic review of clinical trials. Cancer Causes Control, 22, 811-826. 
Wood, S.L., Pernemalm, M., Crosbie, P.A., Whetton, A.D. (2014). The role of the tumor-microenvironment in lung cancer-metastasis and its relationship to potential therapeutic targets. Cancer Treat Rev, 40 (4), 558-566.

World Cancer Research Fund/American Institute for Cancer Research (2007). Food, Nutrition, Physical Activity, and the Prevention of Cancer: a Global Perspective. Washington, DC: AICR.

Wright, R.M., McManaman, J.L., Repine, J.E. (1999). Alcohol-induced breast cancer: a proposed mechanism. Free Radic Biol Med, 26, 348-354.

Wu, W., Yin, Z.H., Guan. P., Ren, Y.W., Zhou, B.S. (2014a). Association of oral contraceptives use and lung cancer risk among women: an updated meta-analysis based on cohort and case-control studies. Asian Pac J Cancer Prev, 15, 1205-1210.

Wu, X.M., Chen, Y., Shao, Y., Zhou, X.L., Tang, W.R. (2014b). Association between cigarette smoking and RASSF1A gene promoter hypermethylation in lung cancer patients: a meta-analysis. Asian Pac J Cancer Prev, 15 (9), 8451-8454.

Yang, Y., Dong, J., Sun, K., Zhao, L., Zhao, F., Wang, L., et al. (2013). Obesity and incidence of lung cancer: a meta-analysis. Int J Cancer, $132(5), 1162-1169$.

Yano, T., Haro, A., Shikada, Y., Maruyama, R., Maehara, Y. (2011). Non-small cell lung cancer in never smokers as a representative "non-smoking-associated lung cancer" epidemiology and clinical features. Int J Clin Oncol, 16 (4), 287-293.

Yeon, J.Y., Suh, Y.J., Kim, S.W., Baik, H.W., Sung, C.J., Kim, H.S., et al. (2011). Evaluation of dietary factors in relation to the biomarkers of oxidative stress and inflammation in breast cancer risk. Nutrition, 27, 912-918.

Yuan, H.L., Liu, X.L., Dai, Q.C., Song, H. (2015). Exogenous natural glycoprotein multiple mechanisms of anti-tumor activity. Asian Pac J Cancer Prev, 16, 1331-1336.

Yuan, J.M., Gao, Y.T., Murphy, S.E., Carmella, S.G., Wang, R., Zhong, Y., et al. (2012). Urinary levels of cigarette smoke constituent metabolites are prospectively associated with lung cancer development in smokers. Cancer Res, 71, 6749-6757.

Zahir, S.T., Mirtalebi, M. (2012). Survival of patients with lung cancer, Yazd, Iran. Asian Pac J Cancer Prev, 13, 4387-4391.

Zhong, S., Ma, T., Chen, L., Chen W., Lv M., Zhang X., et al. (2016). Physical activity and risk of lung cancer: a meta-analysis. Clin J Sport Med, 26 (3), 173-181.

Cite this article aS: Kruk, J., Aboul-Enein, B.H. (2016). The Associations of Selected Lifestyle Patterns and Lung Cancer Risk: An Evidence-based Update. Central European Journal of Sport Sciences and Medicine, 14 (2), 37-53. DOI: 10.18276/cej.2016.2-05. 
